\title{
Atividade antiviral do extrato de própolis contra o calicivírus felino, adenovírus canino 2 e vírus da diarréia viral bovina
}

\author{
Antiviral activity of propolis extracts against feline calicivirus, canine adenovirus 2 , and bovine viral \\ diarrhea virus
}

\author{
Ana Paula Cueto ${ }^{I}$ Sydney Hartz Alves ${ }^{I}$ Marciele Pilau $^{I}$ Rudi Weiblen ${ }^{I I}$ Thaís Felli Kubiça \\ Luciane Teresinha Lovato ${ }^{I^{*}}$
}

\section{RESUMO}

Dentre as propriedades biológicas da própolis, a atividade antimicrobiana tem merecido destacada atenção. Neste artigo, descreve-se a atividade antiviral de dois extratos etanólicos de própolis (EP1 e EP2) frente aos vírus: calicivírus felino $(F C V)$, adenovírus canino tipo 2 (CAV-2) e vírus da diarréia viral bovina (BVDV). Um dos extratos (EP1) foi obtido por extração etanólica de própolis obtida da região central do Estado do Rio Grande do Sul e o segundo (EP2), obtido comercialmente de uma empresa de Minas Gerais. A análise dos extratos de própolis através da cromatografia líquida de alta eficiência (CLAE) identificou a presença de flavonóides como: rutina, quercetina e ácido gálico. A atividade antiviral bem como a citotoxicidade dos extratos aos cultivos celulares foram avaliadas através do MTT [3- (4,5 dimetiltiazol-2yl)-25-difenil-2H tetrazolato de bromo]. Ambos os extratos evidenciaram atividade antiviral frente ao $B V D V$ e $C A V-2$ quando acrescidos ao cultivo celular anteriormente à inoculação viral. Os extratos foram menos efetivos contra o FCV em comparação aos resultados obtidos com os outros vírus, e a atividade antiviral neste caso foi observada apenas quando a própolis estava presente após a inoculação viral. $O$ extrato obtido no laboratório (EP1) apresentou valores mais altos de índice de seletividade $\left(I S=C C_{50} / C E_{50}\right)$, quando comparado à outra amostra (EP2). Em resumo, a própolis apresentou atividade antiviral frente a três diferentes vírus, o que a torna alvo para o desenvolvimento de novos compostos naturais com atividade antiviral.

Palavras-chave: $C A V-2, F C V, B V D V$.

\section{ABSTRACT}

Propolis is a resinous substance produced by bees for which several biological activities have been attributed. In

\begin{abstract}
this article, the antiviral activity of two propolis extracts was tested against bovine viral diarrhea virus $(B V D V)$, canine adenovirus type $2(C A V-2)$, and feline calicivirus (FCV). One of the extracts was obtained by ethanolic extraction of propolis from the Santa Maria (RS) region, while the other was bought from a Minas Gerais industry. The high efficiency liquid cromatography (HPLC) analysis detected the presence of some flavonoids like rutin, quercetin, and gallic acid. The MTT test was applied in order to detect the citotoxicity and also the antiviral activity. Both extracts showed antiviral activity against $B V D V$ and $C A V-2$ when incubated with the cell cultures before viral inoculation. The extracts were less effective against FCV comparing to the results for the other viruses and, the antiviral activity was observed only when the própolis was present after virus inoculation The extract obtained in the lab showed the highest selectivity index $\left(S I=C C_{50} E C_{50}\right)$. Thus, propolis showed antiviral activity against three different viruses, making it a target for the development of new natural compounds with antiviral activity.
\end{abstract}

Key words: propolis extract, respiratory viruses, calicivirus, adenovirus, $B V D V$.

\section{INTRODUÇÃO}

A própolis é um material resinoso formado por uma mistura de exsudatos de plantas enriquecido com produto de saliva de abelhas e cera (DRAGO et al., 2007; BÚFALO et al., 2009). Dentre suas várias atividades biológicas, requerem destaque as ações antibacteriana, antifúngica, anti-inflamatória, hepatoprotetora, anti-tumoral e anti-oxidante (BURDOCK,

'Departamento de Microbiologia e Parasitologia, Universidade Federal de Santa Maria (UFSM), Av. Roraima 1000, 97105-900, Camobi, Santa Maria, RS, Brasil. E-mail: 1tlovato@gmail.com. *Autor para correspondência.

IIDepartamento de Medicina Veterinária Preventiva, UFSM, Santa Maria, RS, Brasil. 
1998). Este amplo espectro de atividades biológicas se deve à variabilidade de seus componentes químicos, dependentes da espécie vegetal da qual o material é coletado, bem como da época do ano e da localização geográfica (SCHNITZLER et al., 2010b).

A própolis brasileira tem sido alvo de grande interesse internacional, pois o Brasil é o terceiro maior produtor mundial e a qualidade da própolis brasileira é considerada uma das melhores do mundo (NETO et al., 2002). A atividade antimicrobiana da própolis coletada em diferentes localizações geográficas no Brasil já foi descrita por pesquisadores brasileiros (SANTOS et al., 2002; SANTOS et al., 2005; SFORCIN et al., 2000) e estrangeiros; (KUJUMGIEV et al., 1999; BANSKOTA et al., 2001).

A atividade antiviral da própolis e seus derivados já foi avaliada frente a alguns vírus patogênicos ao homem (AMOROS et al., 1992;VYNOGRAD et al., 2000) e a animais (KUJUMGIEV et al., 1999); como o herpesvírus humano tipo 1 (HSV1) (AMOROS et al., 1992; HULEIHEL \& ISANU, 2002) e 2 (HSV2) (VYNOGRAD et al., 2000; SCHINTZLER et al., 2010a), vírus da imunodeficiência humana (HIV) (GEKKER et al., 2005), e vírus da influenza aviária (KUJUMGIEV et al., 1999) evidenciando resultados promissores.

Este artigo descreve a atividade antiviral de dois extratos etanólicos de própolis de duas diferentes origens frente ao calicivírus felino (FCV), adenovírus canino tipo 2 (CAV-2) e vírus da diarréia viral bovina (BVDV). A escolha dos vírus utilizados neste estudo é justificada porque o adenovírus canino tipo 2 (CAV-2) e o calicivírus felino (FCV) são agentes etiológicos de doenças respiratórias nas suas respectivas espécies (BUONAVOGLIA\& MARTELLA, 2007; RADFORD et al., 2007), enquanto o vírus da diarréia viral bovina (BVDV) tem sido bastante utilizado como um modelo de estudos de atividade antiviral para o vírus da hepatite C (HCV) (BUCKWOLD et al., 2003). Embora diferentes atividades tenham sido atribuídas à própolis, esta tem sido utilizada desde a antiguidade, no alívio de afecções respiratórias do homem (NETO et al., 2002). Então a possível aplicabilidade deste extrato, baseado no seu uso em enfermidades respiratórias humanas e o fato de CAV-2 e FCV causarem doenças respiratórias em animais de estimação, fundamentou o presente estudo.

\section{MATERIAL E MÉTODOS}

Extrato etanólico de própolis

Foram utilizados neste trabalho dois extratos de própolis, um preparado a partir de própolis obtida na região central do Rio Grande do Sul, Brasil (EP1), e outro adquirido da empresa Prodapys (Minas Gerais) (EP2). A extração alcoólica da amostra EP1 foi realizada de acordo com a metodologia descrita por Szewczak and Godoy, 1984. O material resinoso contendo própolis foi triturado e, a seguir, submetido à extração com etanol $70 \%$ (relação de $30 \%$ material resinoso e $70 \%$ álcool etílico $70 \%$ ). A mistura foi estocada à temperatura ambiente e protegida da luz por cerca de 45 dias. Após este período, o sobrenadante foi recolhido e utilizado nos experimentos.

Análise do extrato de própolis por CLAE

A cromatografia líquida de alta eficiência (CLAE) foi realizada em cromatógrafo líquido (Shimadzu, Kyoto, Japão) com injetor automático (SIL20A), bombas DGU 20A5 com integrador CBM 20 e detector UV-VIS (DAD-SPD-M20A), Software LC SP1. As análises cromatográficas foram realizadas em condições isocráticas, utilizando coluna C18 $(4,6 \mathrm{mmx} 150 \mathrm{~mm})$ e a fase móvel usada foi metanol/ acetonitrila/água (40:15:45), contendo $1 \%$ ácido acético. O fluxo e o volume de injeção foram de $0,9 \mathrm{~mL} \mathrm{~min}^{-1} \mathrm{e}$ $20 \mu \mathrm{L}$, respectivamente. A leitura foi executada em comprimento de onda de $257 \mathrm{~nm}$. Essas técnicas foram realizadas no Departamento de Farmácia Industrial da UFSM. Os constituintes foram analisados conforme descrito por BOLIGON et al. (2009).

\section{Cultivos celulares e vírus}

Foram utilizados três tipos de cultivos celulares: MDBK (células de linhagem de rim bovino), MDCK (células de rim canino) e CRFK (células de rim felino). As células foram cultivadas em meio essencial mínimo (MEM), contendo $10 \%$ de soro fetal bovino, penicilina, estreptomicina e anfotericina $\mathrm{B}$, nas concentrações de $100 \mathrm{U} \mathrm{mL}^{-1}, 100$ e $2,5 \mu \mathrm{g} \mathrm{mL}^{-1}$, respectivamente. Para as células MDBK, utilizou-se soro equino. As células foram mantidas em estufa a $37^{\circ} \mathrm{C}$ com $5 \%$ de $\mathrm{CO}_{2}$. Para a realização dos testes, foram preparadas culturas de células em microplacas de poliestireno rígido com 96 cavidades de fundo plano. As cepas dos vírus da diarréia viral bovina (BVDV) citopático Singer genótipo 1, adenovírus canino tipo 2 (CAV2) e calicivírus felino (FCV) foram fornecidas pelo Setor de Virologia/UFSM. Os estoques dos vírus foram preparados e titulados de acordo com a metodologia descrita por (DEZENGRINI et al., 2006) e as alíquotas mantidas a $-70^{\circ} \mathrm{C}$ até o momento do uso.

Ensaios de citotoxicidade

Os testes foram realizados em microplacas de poliestireno com 96 cavidades, em duplicata, e 
repetidos três vezes. As células foram colocadas nas placas e incubadas por 24 horas a $37^{\circ} \mathrm{C}$. A citotoxicidade foi avaliada pelo teste de MTT (3-(4,5 dimetiltiazol-2yl)2-5-difenil-2H tetrazolato de bromo), descrito por MOSMANN (1983) e modificado por PILAU (2010). Resumidamente, alíquotas de $200 \mu 1$, contendo 1500 ; $750 ; 375 ; 187,5 ; 93,75 ; 46,8 ; 23,4 ; 11,7 \mu \mathrm{g} \mathrm{ml}^{-1}$ do extrato de própolis foram dispensados sequencialmente nas placas de microtitulação. Controles celulares e de toxicidade do etanol foram incluídos. Após três dias de incubação, os meios de cultivo foram removidos e a viabilidade das células foi determinada através da densidade ótica por leitura em espectrofotômetro com $\lambda=540 \mathrm{~nm}$. A concentração de cada extrato de própolis que resultou em $50 \%$ de toxicidade $\left(\mathrm{CC}_{50}\right)$ foi determinada através de uma curva dose resposta.

\section{Atividade antiviral}

Para a avaliação da atividade antiviral dos extratos de própolis (EP1 e EP2), utilizaram-se técnicas semelhantes às utilizadas nos ensaios de citotoxicidade. Os diferentes cultivos celulares foram infectados com vírus ( $25 \mu \mathrm{l} /$ poço contendo 100 TCID50) e, a seguir, incubados a $37^{\circ} \mathrm{C}$ com $5 \%$ de $\mathrm{CO}_{2}$ durante duas horas, quando, então, o inóculo foi retirado. Nesses testes, incluiu-se ainda o controle celular (célula e meio) e o controle do vírus (meio, célula, vírus). Os extratos foram adicionados: I) antes da inoculação viral (1h de contato célula/extrato); II) após a inoculação viral (extratos adicionados após a inoculação viral e mantidos) e; III) adicionados antes e após a inoculação viral. Em todos os tratamentos, foram utilizadas as mesmas concentrações de extrato de própolis citadas acima. Após três dias de incubação, os meios de cultivo foram removidos e a viabilidade das células determinada através da densidade ótica por leitura em espectrofotômetro $\lambda=540 \mathrm{~nm}$. Nessas condições, foi determinada a concentração efetiva a 50\% (CE50), que representa a concentração do extrato de própolis capaz de inibir o efeito citopático do vírus em $50 \%$. Posteriormente, foi determinado o índice de seletividade (IS), que é dado pela fórmula IS $=\mathrm{CC}_{50} /$ $\mathrm{CE}_{50}$.

\section{RESULTADOS E DISCUSSÃO}

As análises dos extratos de própolis (EP1 e EP2) utilizados no presente experimento estão apresentadas na figura 1 . Os dados obtidos com os testes de citotoxicidade e inibição viral realizados em cultivo celular são apresentados na tabela 1 . A análise do extrato de própolis através da cromatografia líquida de alta eficiência (CLAE) identificou a presença de flavonóides como: rutina, quercetina e ácido gálico. No cromatograma (Figura 1), é possível visualizar a presença de picos diferentes entre as amostras de extrato de própolis comercial (EP2) e de própolis extraído no laboratório (EP1). Diferenças qualitativas entre as amostras não foram detectadas, uma vez que os três padrões utilizados como controle de qualidade da análise foram detectados em ambas as amostras (EP1 e EP2). Todavia, do ponto de vista quantitativo, detectaram-se diferenças na altura dos picos cromatográficos, sobretudo na fração da rutina.

A própolis é uma substância de composição química complexa e variável em função do tipo de vegetação próxima à colméia (SCHNITZLER et al., 2010a), da época do ano em que foi coletada (PARK et al., 2002) e, ainda, pelas diferentes espécies de abelhas produtoras (SILICI \& KUTLUCA, 2005). A análise cromatográfica de 150 amostras provenientes dos três estados da região sul do Brasil, do Uruguai e da Argentina demonstrou a presença de cinco diferentes grupos de composição química da própolis (PARK et al., 2002). Dessa forma, as diferenças observadas na composição das duas amostras de própolis (EP1 e EP2) aqui testadas constituiu-se num resultado, de certa forma esperado, pois são amostras procedentes de regiões brasileiras bem distintas.

A toxicidade dos extratos de própolis estudados frente aos cultivos celulares variou entre as diferentes linhagens de células bem como entre estes extratos (Tabela 1). O extrato de própolis comercialmente disponível (EP2) evidenciou menor toxicidade quando comparado ao extrato obtido em nosso laboratório (EP1). Ambos os extratos demonstraram maior toxicidade frente à linhagem de células de rim canino (MDCK), quando comparados à linhagem de células de rim bovino (MDBK). Isso determinou que se utilizassem tais extratos em elevadas diluições, pois, na concentração original, esses extratos demonstraram toxicidade incompatível com a manutenção de cultivos celulares viáveis. Assim, a concentração inicial utilizada nos ensaios foi, aproximadamente, 200 vezes menor que a dos extratos originais a $15 \%$.

$\mathrm{O}$ efeito citotóxico dos extratos originais utilizados nos testes aqui descritos não era esperado. $\mathrm{O}$ fato de ser um produto natural e a possível ausência de toxicidade para o homem e animais são vantagens atribuídas à própolis. Contudo, o efeito citotóxico das amostras de própolis em diferentes cultivos celulares tem sido descrito desde moderado até altamente tóxico (HULEIHEL \& ISANU, 2002; SCHNITZLER et al., 2010a). O extrato aquoso de própolis em uma concentração de $10 \%$ não apresentou toxicidade para a linhagem celular de rim de macaco verde africano 


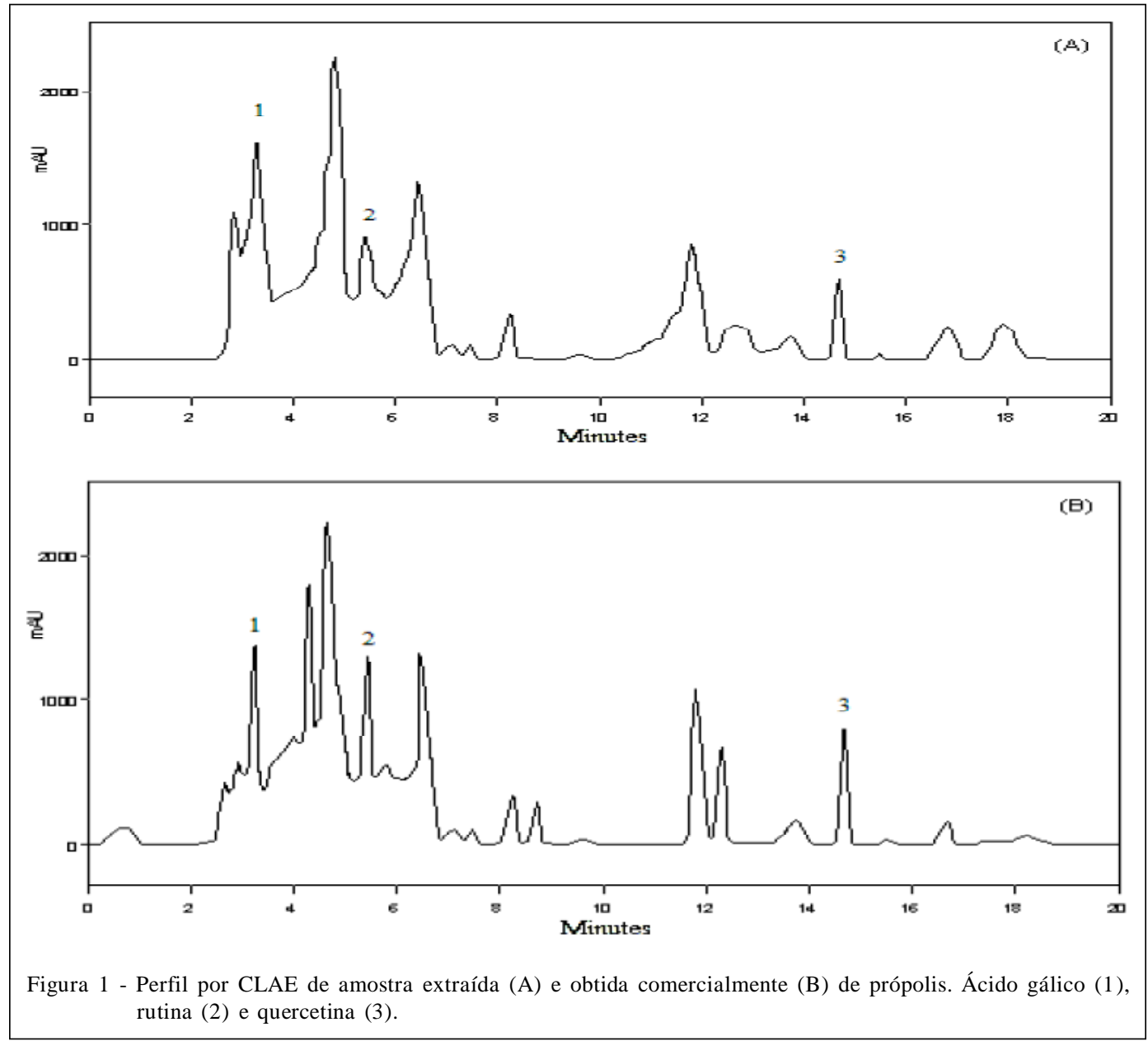

(Vero), e o mesmo extrato a $20 \%$ não evidenciou efeitos adversos, quando inoculado em coelhos e camundongos (HULEIHEL \& ISANU, 2002). Entretanto, o extrato aquoso de própolis utilizado em outro teste antiviral também com células de rim de macaco verde africano de outra linhagem (RC-37) demonstrou uma concentração máxima não-tóxica de apenas $0,03 \%$ (SCHNITZLER et al., 2010a). A toxidez da própolis frente a algumas células de origem tumoral, como as células de carcinoma epidermóide laringeal humano (HEp-2) (BÚFALO et al., 2009), e a tumores experimentais induzidos em animais têm sugerido um efeito antitumoral para esta substância. Efeito citotóxico seletivo para células tumorais também já foi demonstrado para o éster fenetil ácido cafeico (CAPE) um dos constituintes da própolis (LEE et al., 2005).

Conforme já detalhado em Material e Métodos, os extratos foram adicionados antes e após a inoculação viral. Os resultados apresentados na tabela 1 evidenciam melhor atividade antiviral quando os extratos são agregados no pré-tratamento; a atividade do extrato obtido no próprio laboratório (EP1) foi superior à do extrato obtido comercialmente (EP2). Ambos os extratos de própolis examinados apresentaram uma melhor atividade frente ao BVDV do que frente aos outros dois vírus, embora as diferenças de atividades entre BVDV e CAV-2 tenham sido pequenas (Tabela 1). O BVDV possui um envelope lipídico envolvendo o nucleocapsídeo (BUCKWOLD et al., 2003), o que se constitui numa diferença estrutural em relação aos outros dois vírus estudados, fato que pode ter determinado a maior sensibilidade deste vírus à ação antiviral dos extratos.

Os estudos sobre a atividade antiviral dos extratos de própolis têm produzido resultados díspares. Extratos aquosos e etanólicos de própolis demonstraram boa atividade antiviral sobre herpes simplex tipo 1 (HSV-1) (HULEIHEL \& ISANU, 2002; SCHNITZLER et al., 2010a) e tipo 2 (HSV-2) (SCHNITZLER et al. (2010b) em diferentes 
Tabela 1 - Citotoxicidade e atividade antiviral do extrato de própolis frente ao vírus da diarréia viral bovina (BVDV), adenovírus canino tipo 2 (CAV-2) e calicivírus felino (FCV).

\begin{tabular}{|c|c|c|c|c|c|c|c|c|}
\hline \multirow[b]{2}{*}{ Extrato } & \multirow[b]{2}{*}{ Vírus } & \multicolumn{3}{|c|}{ Pré tratamento } & \multirow{2}{*}{$\begin{array}{l}\text { Pós tratamento } \\
\qquad \mathrm{CE}_{50}\end{array}$} & \multicolumn{3}{|c|}{ Pré e Pós tratamento } \\
\hline & & $\mathrm{CC}_{50}$ & $\mathrm{CE}_{50}$ & IS & & IS & $\mathrm{CE}_{50}$ & IS \\
\hline \multirow[t]{3}{*}{ Extraído } & BVDV & 293 & 21,7 & 13,5 & 111,7 & 2,6 & - & - \\
\hline & CAV & 227 & 24,3 & 9,3 & 98 & 2,3 & 100 & 2,3 \\
\hline & FCV & 251 & sa & sa & 79,3 & 3,2 & 47 & 5,3 \\
\hline \multirow[t]{3}{*}{ Comercial } & BVDV & 343 & 54,4 & 6,3 & 85,5 & 4 & - & - \\
\hline & CAV- & 330 & 55,2 & 6 & 67,5 & 4,8 & 146 & 2,3 \\
\hline & FCV & 295 & sa & sa & 80 & 3,7 & 68 & 4,3 \\
\hline
\end{tabular}

* valores expressos em $\mu \mathrm{g} \mathrm{m}{ }^{-1}$; ,sa: sem atividade; $\mathrm{CC}_{50}=$ concentração citotóxica $50 \%$; $\mathrm{CE}_{50}=$ concentração efetiva $50 \%$; índice de seletividade IS $=\mathrm{CC}_{50} / \mathrm{CE}_{50}$.

oportunidades. HULEIHEL \& ISANU (2002) obtiveram uma proteção quase total frente ao efeito citopático do HSV-1 em células Vero com a adição de extrato aquoso de própolis às células 2 horas antes ou no momento da inoculação viral. Por outro lado, SCHNITZLER et al. (2010a) e SCHNITZLER et al. (2010b) demonstraram que extratos etanólicos e aquosos de própolis causavam uma redução $>90 \%$ na formação de placas in vitro pelo HSV-1 e HSV-2, respectivamente. Entretanto, nesses dois últimos estudos citados, a atividade antiviral foi observada quando os vírus testados foram tratados com o extrato antes de serem colocados em contato com as células, mas não com o pré-tratamento das células (SCHNITZLER et al., 2010a; SCHNITZLER et al., 2010b).

A própolis e seus derivados já foram testados também frente ao HIV, apresentando resultados promissores (GEKKER et al., 2005). Extratos etanólicos de própolis oriundos de várias regiões geográficas inibiram a expressão viral do HIV em células da micróglia e linfócitos TCD4+ (GEKKER et al., 2005). Com base em ensaios que quantificam a fusão do HIV à membrana celular, foi demonstrado que o mecanismo antiviral da própolis envolveu a inibição da entrada viral nas células (GEKKER et al., 2005).

A discordância de resultados entre estudos sobre a atividade antiviral da própolis repousa sobre o grande número de variáveis que tais testes envolvem, notadamente: origem da própolis, processo de extração, composição química, cultivos celulares e vírus escolhidos. Nesse rol, destaca-se a variável composição química, podendo ser tão complexa quanto as comparações entre extratos de espécies vegetais de diferentes famílias botânicas (BANKOVA et al., 1995). No entanto, existe um ponto comum entre os resultados obtidos por diferentes pesquisadores frente ao HSV-1 e 2, o HIV, e os resultados aqui apresentados. Em todos os casos, os extratos de própolis mostraram sua melhor atividade em algum passo anterior à entrada do vírus na célula (Tabela 1), (HULEIHEL \& ISANU, 2002; GEKKER et al., 2005; SCHNITZLER et al., 2010a; SCHNITZLER et al., 2010b). É importante salientar que em todos os experimentos citados acima apenas um vírus estava sendo testado, ou seja, o HSV ou HIV (HULEIHEL \& ISANU, 2002; GEKKER et al., 2005; SCHNITZLER et al., 2010a; SCHNITZLER et al., 2010b); enquanto, no trabalho aqui descrito, foram testados diferentes vírus no mesmo experimento (Tabela 1).

Seguindo a avaliação geral dos resultados obtidos, pôde-se observar uma melhor atuação do extrato obtido no próprio laboratório em comparação ao extrato obtido comercialmente (Tabela 1). Divergências na atividade antimicrobiana de extratos de própolis de diferentes procedências têm sido amplamente relatadas (HULEIHEL \& ISANU, 2002; GEKKER et al., 2005; SCHINTZLER et al., 2009; SCHNITZLER et al., 2010b) e, em muitos casos, têm sido atribuídas à diferença na composição química principalmente no que se refere ao conteúdo de flavonóides (SCHINTZLER et al., 2009; SCHNITZLER et al., 2010b).

A indicação do extrato de própolis como um medicamento contra os vírus de cães e gatos estudados ainda não é possível apenas com os resultados aqui demonstrados. Todavia, a eficaz atividade antiviral desse extrato sobre o CAV-2 (Tabela 1) evidencia um potencial que deveria ser levado em consideração, principalmente pelo fato de que não existem medicamentos disponíveis contra esse vírus (BUONAVOGLIA\& MARTELLA, 2007) e também pelo fato de que a busca por terapias para doenças de animais de estimação têm aumentado. Por outro lado, a atuação dos extratos sobre o BVDV sugere uma possível atividade sobre o $\mathrm{HCV}$, uma vez que o BVDV 
tem sido estudado como modelo para $\mathrm{HCV}$ (BUCKWOLD et al., 2003).

\section{CONCLUSÃO}

Os extratos de própolis testados neste artigo demonstraram atividade antiviral frente a três diferentes vírus de origem animal, evidenciando seu potencial para o desenvolvimento de novos compostos naturais com ação antiviral.

\section{REFERÊNCIAS}

AMOROS, M. et al. Synergistic effect of flavones and flavonols against herpes simplex virus type 1 in cell culture. Comparison with the antiviral activity of propolis. J Nat Prod, v.55, n.12, p.1732-1740, 1992.

BANKOVA, V. et al. Chemical composition and antibacterial activity of Brazilian propolis. Z Naturforsch C, v.50, n.3-4, p.167-172, 1995.

BANSKOTA, A.H. et al. Hepatoprotective and antiHelicobacter pylori activities of constituents from Brazilian propolis. Phytomedicine, v.8, n.1, p.16-23, 2001. Disponível em: <http://www.urbanfischer.de/journals/phytomed>. Acesso em: 9 mar. 2011. doi: 0944-7113/01/08/01-016.

BOLIGON, A. et al. Antioxidant activities of flavonol derivatives from the leaves and stem bark of Scutia buxifolia Reiss. Bioresource Technol, v.100, n.24, p.6592-6598, 2009. Disponível em: 〈http://dx.doi.org.ez47.periodicos.capes.gov.br〉. Acesso em: 28 abr. 2011. doi: doi:10.1016/ j.biortech.2009.03.091.

BUCKWOLD, V.E. et al. Bovine viral diarrhea virus as a surrogate model of Hepatitis $\mathrm{C}$ virus for the evaluation of antiviral agents. Antiviral Res, v.60, n.1, p.1-15, 2003. Disponível em: <http:// www.sciencedirect.com/science?_ob=MImg\&_imagekey=B6T2H49 CTCPS $-1-1$ P\&_cdi $=4919 \&$ \& user $=687358 \&$ \& pii $=$ S 0 $166354203001748 \&$ _origin $=$ gateway \&_coverDa te $=09 \% 2 F 30 \% 2 F 2003 \& \_s k=999399998 \& v i e w=c \& w c h p=d G L b V z z-$ zSkWb\&md5=abb4ff7a $17 \mathrm{bcd} 9 \mathrm{ec} 3 \mathrm{~b} 83 \mathrm{cae} 725833119 \& \mathrm{ie}=/$ sdarticle.pdf>. Acesso em: 9 mar. 2011. doi: 10.1016/S01663542(03)00174-8.

BÚFALO, M.C. et al. In vitro cytotoxic effect of Brazilian green propolis on human laryngeal epidermoid carcinoma (HEp2) cells. Evid Based Complement Alternat Med, v.6, n.4, p.483-487, 2009. Disponível em: <www.hindawi.com/journals/ ecam/2009/659784/abs/>. Acesso em: 26 jul. 2011. doi: $10.1093 /$ ecam/nem 147 .

BURDOCK, G.A. Review of the biological properties and toxicity of bee propolis (propolis). Food Chem Toxicol, v.36, n.4, p.347-363, 1998. Disponível em: <http://

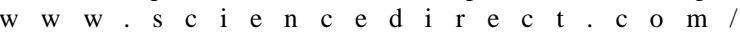
science?_ob=MImg\&_imagekey $=$ B 6 T 6 P-41FVN8W-B -

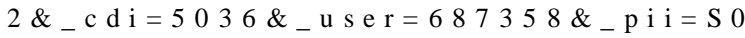
$278691597001452 \&$ \&origin $=$ gateway $\&$ _coverDate $=$ 04\%2F06\%2F1998\&_sk=999639995\&view=c\&wchp=dGLbVtbzSkWA\&md5=8007d4d04cab6fe7c0e8439391 c4c178\&ie $=/$ sdarticle.pdf $>$. Acesso em: 9 mar. 2011. doi:10.1016/S02786915(97)00145-2.
BUONAVOGLIA, C; MARTELLA, V. Canine respiratory viruses. Vet Res, v.38, p.355-373, 2007. Disponível em: <http://dx.doi.org/10.1051/vetres:2006058>. Acesso em: 9 mar. 2011. doi: $10.1051 /$ vetres:2006058

DEZENGRINI, R. Soroprevalência de nfecções víricas em cães de Santa Maria, RS; e seleção e caracterização de linhagens celulares resistentes ao vírus da diarréia viral bovina. 2006. 63f. Dissertação (Mestrado em Medicina Veterinária) - Universidade Federal de Santa Maria, Santa Maria, RS.

DRAGO, L. et al. In vitro activity of a novel própolis formulation (Actichelated própolis). J Appl Microbiol, v.103, n.5, p.19141921, 2007. Disponível em: <http://onlinelibrary.wiley.com/ doi/10.1111/j.1365-2672.2007.03421.x/abstract>. Acesso em: 9 mar. 2011. doi: 10.1111/j.1365-2672.2007.03421.x.

GEKKER G. et al. Anti-HIV-1 activity of propolis in CD4(+) lymphocyte and microglial cell cultures. J Ethnopharmacol, v.102, n.2, p.158-162, 2005. Disponível em: <http:www.elsevier.com/locate/jethpharm>. Acesso em: 9 mar. 2011. doi:10.1016/j.jep.2005.05.045.

HULEIHEL, M.; ISANU, V. Anti-herpes simplex vírus effect of an aqueous extract of própolis. Isr Med Assoc J, v.4, n.11, p.923-927, 2002.

KUJUMGIEV, A. et al. Antibacterial, antifungal and antiviral activity of propolis of different geographic origin. $\mathbf{J}$ Ethnopharmacol, v.64, n.3, p.235-240, 1999. Disponível em: 〈http:www.elsevier.com/locate/jethpharm>. Acesso em: 9 mar. 2011. doi:10.1016/S0378-8741(98)00131-7.

LEE, S.-J. et al. Identification of volatile components in basil (Ocimum basilicum 1.) and thyme leaves (Thymus vulgaris 1.) and their antioxidant properties. Food Chem, v.91, p.131137, 2005. Disponível em: <http:www.elsevier.com/locate/ foodchem>. Acesso em: 10 mar. 2011. doi:10.1016/ j.foodchem.2004.05.056.

MOSMANN, T. Rapid colorimetric assay for cellular growth and survival: application to proliferation and cytotoxicity assays. J Immunol Methods, v.65, n.1-2, p.55-63, 1983.

NETO, F.R.A et al. Própolis: 100 anos de pesquisa e suas perspectivas futuras. Quím Nova, v.25, n.2, p.321-326, 2002.

PARK, Y.K. et al. Própolis produzida no sul do Brasil, Argentina e Uruguai: evidências fitoquímicas de sua origem vegetal. Cienc Rural, v.32, n.6, p.997-1003, 2002. Disponível em: <http:// www.scielo.br/scielo.php? script $=$ sci_arttext $\&$ pid $=$ S0 103 $84782002000600013 \& \operatorname{lng}=e n \& n r m=i s o>$. Acesso em: 11 mar. 2011. doi: 10.1590/S0103-84782002000600013.

PILAU, M. Atividade de óleos essenciais de condimentos frente a Herpesvírus, Flavivírus, Paramyxovírus e Reovírus. 2010. 115f. Dissertação (Mestrado em Ciências Farmacêuticas) - Universidade Federal de Santa Maria, Santa Maria, RS.

RADFORD, A.D.et al. Feline Calicivirus. Vet Res, v.38, n.2, p.319-335, 2007. Disponível em: <http://dx.doi.org/10.1051/ vetres:2006056>. Acesso em: 9 mar. 2011. doi: 10.1051/ vetres: 2006056 . 
SANTOS, F.A. et al. Antibacterial activity of Brazilian propolis and fractions against oral anaerobic bacteria. $\mathbf{J}$ Ethnopharmacol, v.80, n.1, p.1-7, 2002. Disponível em: <http:www.elsevier.com/locate/jethpharm>. Acesso: 9 mar. 2011. doi:10.1016/S0378-8741(02)00003-X.

SANTOS, V.R. et al. Oral candidiasis treatment with Brazilian ethanol propolis extract. Phytother Res, v.19, n.7, p.652654, 2005. Disponível em: <http:www.interscience.wiley.com>. Acesso em: 10 mar. 2011. doi: 10.1002/ptr.1715.

SCHNITZLER, P. et al. Antiviral activity and mode of action of propolis extracts and selected compounds. Phytother Res, v.24, n.1, p.20-28, 2010a. Disponível em: <http:www.interscience.wiley.com>. Acesso em: 10 mar. 2011. doi: $10.1002 /$ ptr.2868.

SCHNITZLER, P. et al. Mechanism of herpes simplex virus type 2 suppression by propolis extracts. Phytomedicine, v.17, n.2, p.132-138, 2010b. Disponível em: <http:www.elsevier.de/ phymed>. Acesso em: 10 mar. 2011. doi:10.1016/ j.phymed.2009.07.006.
SZEWCZAK, E.H.; GODOY, G.F. Estudo comparativo entre a sensibilidade de Staphylococcus aureus à própolis e a antibióticos. Apicultura no Brasil, v.3, n.17, p.28-29, 1984.

SILICI, S.; KUTLUCA S. Chemical composition and antibacterial activity of propolis collected by three different races of honeybees in the same region. J Ethnopharmacol, v.99, n.1, p.69-73, 2005. Disponível em: <http:www.elsevier.com/locate/ jethpharm>. Acesso em: 10 mar. 2011. doi:10.1016/ j.jep.2005.01.046.

SFORCIN, J.M. et al. Seasonal effect on Brazilian propolis antibacterial activity. J Ethnopharmacol, v.73, n.1-2, p.243-249, 2000. Disponível em: <http:www.elsevier.com:locate:jethpharm>. Acesso em: 10 mar. 2011. doi: 10.1016/S0378-8741(00)00320-2.

VYNOGRAD, N. et al. A comparative multi-centre study of the efficacy of propolis, acyclovir and placebo in the treatment of genital herpes (HSV). Phytomedicine, v.7, n.1, p.1-6, 2000 . 